\title{
Estimated Systolic Blood Pressure
}

National Cancer Institute

\section{Source}

National Cancer Institute. Estimated Systolic Blood Pressure. NCI Thesaurus. Code C139031.

A quantitative estimate of the pressure in a given cardiovascular structure during ventricular systole. 